\title{
Article \\ Efficiency Comparison of hydro turbines in a micro generator system from free-flow vortex
}

\author{
Piyawat Sritram ${ }^{1}$, and Ratchaphon Suntivarakorn ${ }^{1, *}$ \\ 1 Department of Mechanical Engineering, Faculty of Engineering, KhonKaen University, KhonKaen, Thailand \\ 40002; sritram_1111@hotmail.com (P.S.) \\ * Correspondence: Ratchaphon@kku.ac.th
}

\begin{abstract}
This study aimed to enhance a micro hydroelectric generator system driven by free-flow vortex and to compare efficiency of Propeller and Crossflow turbines. Series of turbines in each type were designed and tested at water-flowrate of $0.02 \mathrm{~m}^{3} / \mathrm{s}$. The turbine housing has 1 meter in diameter and 0.5-meter height with 2 meters outlet drain at the bottom. The best efficiency extracted from Crossflow turbines with the same height $(0.3$ meter) but different in diameter $(0.4,0.5,0.6$, and 0.7 meter) and numbers of blade $(12,18,24,30$, and 23$)$ was from an 18 blades turbine at $23.01 \%$ of efficiency. The best efficiency extracted from Propeller turbines with 5 blades was from a 0.4-meterhigh turbine with a diameter of 0.7 meter at $13.92 \%$ of efficiency. There were 12 Propeller turbines designed in this study. They were different in height $(0.2,0.3$, and 0.4 meter $)$ and, in each height, 0.4, 0.5, 0.6, and 0.7 of diameter was applied. The result revealed that Cross Flow turbine had more efficiency to the system than Propeller turbine (9.09\%) at the water-flowrate of $0.02 \mathrm{~m}^{3} / \mathrm{s}$
\end{abstract}

Keywords: Gravitational vortex; Free-flow vortex; Cross flow turbine; Propeller turbine.

\section{Introduction}

From studies, situations, and problems of power consumption from around the world today, there will be power shortages as well as a massive pollution impacts in the near future. Hence, alternate sources of power are widely concerned. Hydropower, for instance, is one of best choice to be an alternative energy. It is also considered to be "clean energy" without any harms to the environment. There are also many research and developments on Hydroelectricity innovations in transportation business and power industries.

Recently, because $71 \%$ of the earth surface is covered with water, Hydroelectricity is one of the most interesting technology for harvesting unlimited power from natural water sources as well as harvesting power from the sun and the wind. Moreover, water is one of the cheapest sources of power that emits $0 \%$ of carbon-dioxide [1]. A micro generator system from waterpower can be designed to generate enough power for houses, a plantation, and a small village [2]. One important advantage of this micro-power generator system is that the electric power output can be predicted due to the weather forecasting [3] and it has positive impact on the environment [4]. This has stirred up wide interests in seeking the most efficient technology to gather power form water sources. Although, there are plenty of huge practical hydroelectric power plants all around Europe, yet they're still considered to be harmful to the environment [5]. Hence, harvesting electric energy from small and all-year free-flow water sources becomes an alternative way in finding super clean energy. Now, there are two ways of producing electric power from small water sources: Bypass method and Open Canal method. The Bypass method channels or bypasses water from an irrigation canal into a power generator system. The Open method is to install a power generator system into a canal. The advantage of Bypass method is that 
the expelled water from the system goes directly back to the canal and later can be consumed or used. Many researchers and inventors are now interested in this method. They are now applying free-flow vortex pattern as a source of kinetic power to drive the generator. The kinetic power is generated from the vortex that flows vertically from above through Gravitational vortex power turbine in a cylinder-shaped housing with a drainage at the bottom. This system can obviously speed up the water flow and transform it into kinetic power to propel the turbine [6-7]. Franz Zotloterer is the first one among inventors in this field of study to develop vortex powered generator [8]. He has built the Low-head Power Plant driven by kinetic power from free-flow vortex through cylinder-shaped hydroelectric generator.

This study aimed to enhance a micro hydroelectric generator system driven by kinetic power from free-flow vortex. Two types of turbines (Propeller and Crossflow) were designed to the system and tested to identify theirs' efficiency. Bypass method was applied to feed free-flow vortex to the system [8].

The researcher has designed a system that controls water-flow activity for the generator. To induct more water flow speed to the system, an inlet (water path) with narrowedangle end was designed (see figure 1). The generator had a cylinder-shaped housing with 1 meter in diameter and a round-shaped drainage ( 0.2 meter in diameter). This design has been proved to induct vortex at the fastest speed [9]. With the design of the water flow activity, the earth gravity was also applied to boost up vortex speed inducted from lowhead water sources [10-11]. These had created sufficient kinetic energy to propel the turbines tested in the system.

There are numerous researches about factors that affect hydroelectric power generator system from free-flow vortex [12] such as (1) the turbine housing design [13-14], (2) the proper turbine type for free-flow vortex [15-16], best turbine materials [17], number of propeller bade (5 blades) that achieves most efficiency [15], and (3) other factors involving Fluid Dynamics studies that effect generator system efficiency [18-20]. A study on efficiency comparison between two types of turbine blade used in hydroelectric power generator system is a practical add-on to enhance the system for better outcome.

\section{Materials and Methods}

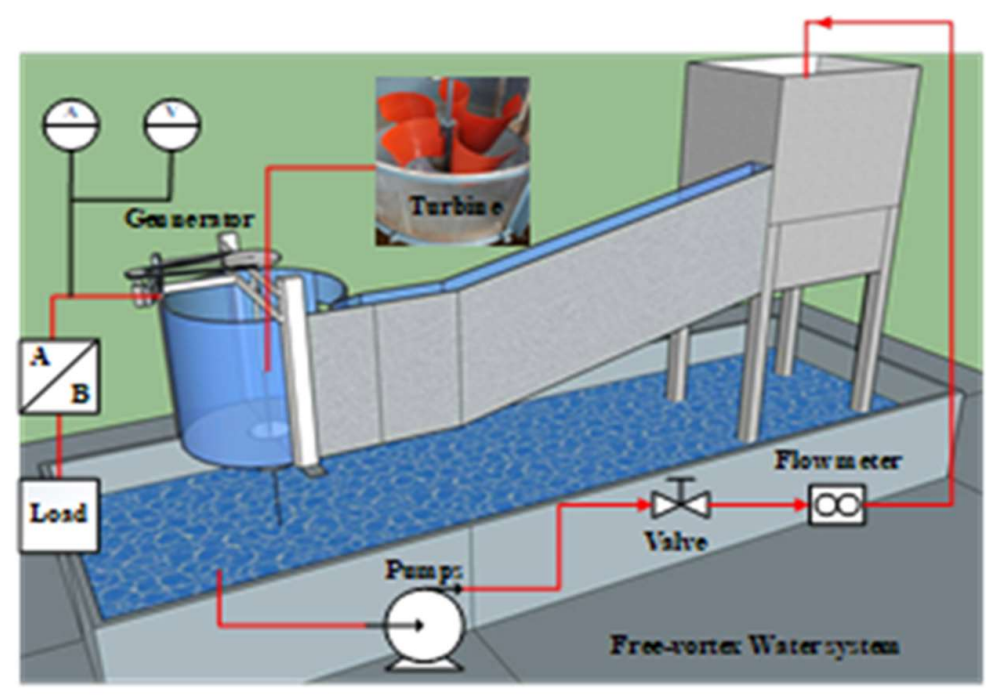

Figure 1. Working diagram

This research was carried out by creating free-flow vortex simulation with a reservoir as a water source. Water inlet was designed to channel the water from a water tank and 
create vortex force into the generator [15-20]. The cylinder-shaped turbine housing was 1 meter in diameter and the height was 0.5 meter with the 0.2 -meter round-shaped drainage at the bottom. The water flow rate of the system ranged from $0.2-0.6 \mathrm{~m}^{3} / \mathrm{s}$ was administered by an adjustable water pump. The series of turbine from each type were hooked up to a transmission that linked to a power generator and a device that can read power output. The turbine testing procedures were performed as follow:

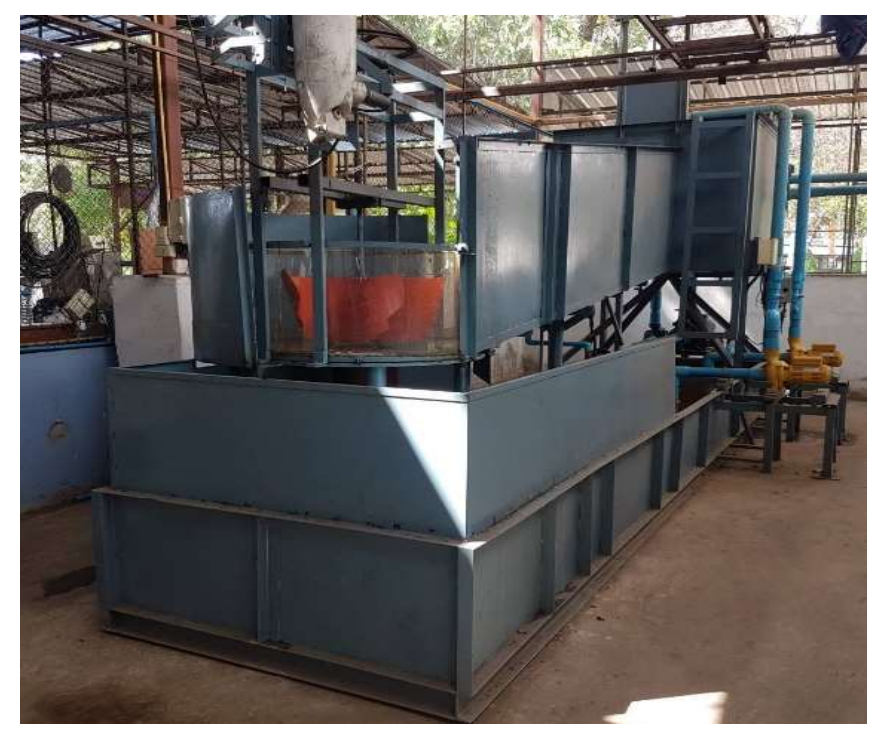

Figure 2. The free vortex hydro power plant.

1. Twelve Propeller turbines that had 5 blades were created (see figure 3 ). They were divided into three different heights of $0.2,0.3$, and 0.4 meter. At each height, there were four different turbines according to theirs' diameter $(0.4,0.5,0.6$, and 0.7$)$. Then, the twelve propeller turbines were installed into the simulation. All of them were tested at different water-flow rate of $0.2,0.3,0.4,0.5$ and $0.6 \mathrm{~m}^{3} / \mathrm{s}$ respectively to identify rpm, water height, voltage, and electric current to access waterpower, power output, and overall efficiency.

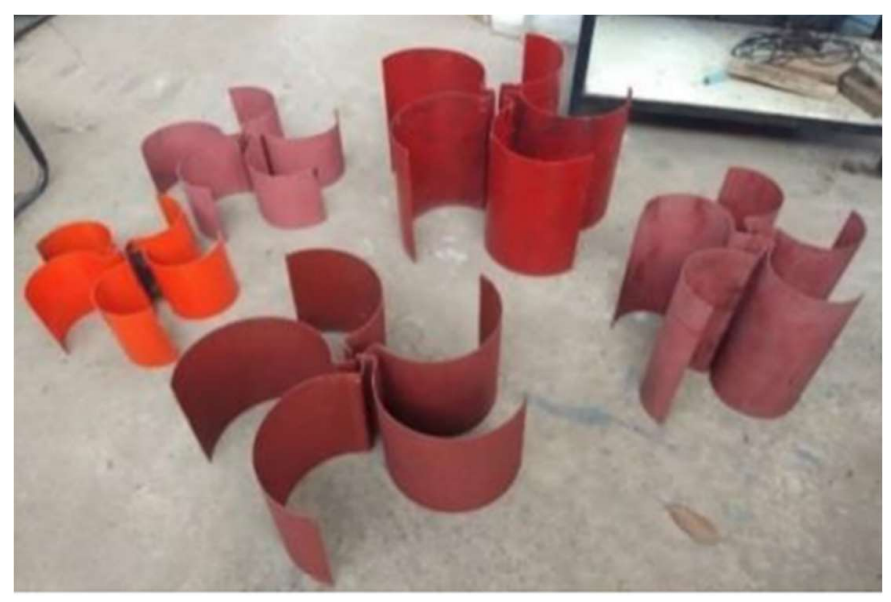

Figure 3. The Propeller turbine tests.

2. Crossflow turbines were created (see figure 4-5). All four turbines in the initial designing stage had 24 blades. Each one was different in diameters $(0.4,0.5,0.6$, and 0.7 
meter) with 0.1-meter blade width [21] and 0.3-meter turbine height. The four turbines were installed into the simulation. All of them were tested at different water-flow rate of $0.2,0.3,0.4,0.5$ and $0.6 \mathrm{~m}^{3} / \mathrm{s}$ respectively to identify rpm, water height, voltage, and electric current to access waterpower, power output, and overall efficiency. When the size of the most efficient Crossflow turbine is identified, the numbers of its' blade had been decreased and added up to 18, 24, 30, and 36 blades respectively. Then, they had been tested through the same method to identify theirs' efficiency.

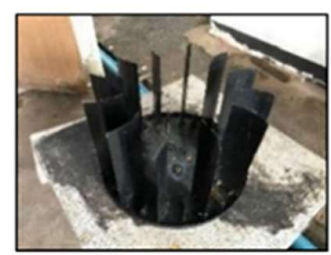

12 blades

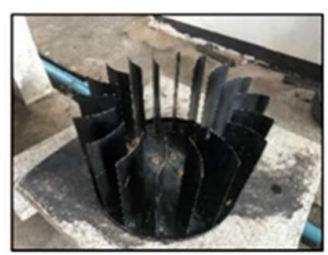

18 blades

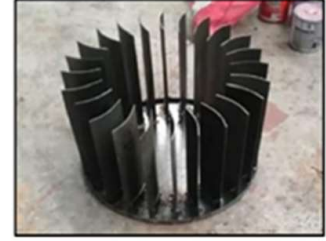

24 blades

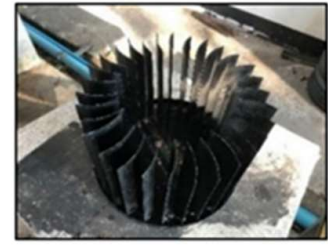

30 blades

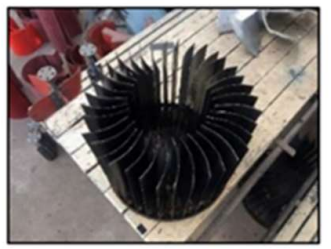

36 blades

Figure 4. Number of turbine blades used in the test.

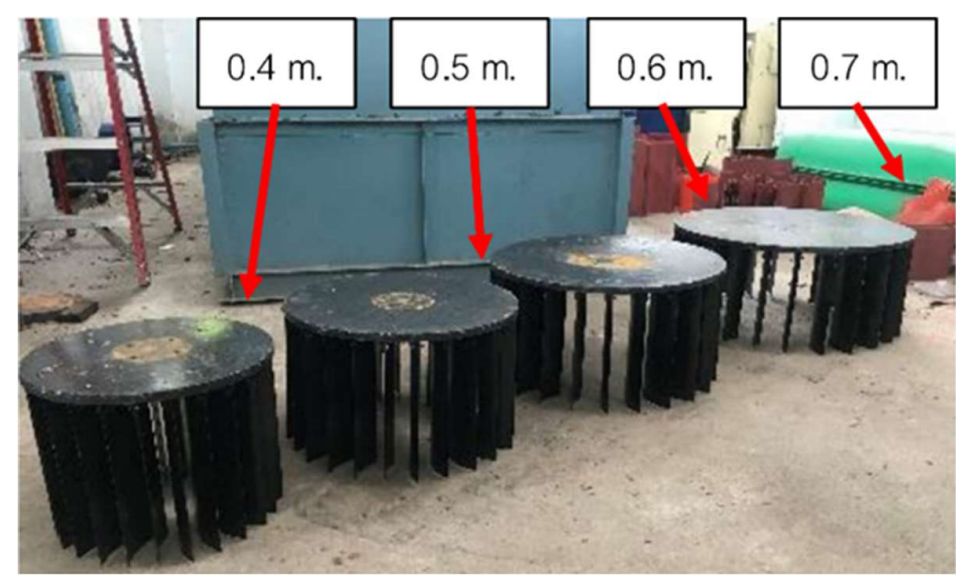

Figure 5. The size of the turbine used in the test.

The most efficient turbines from each type were identified at this point. They had been tested and evaluated in the same setting with the same factors so their performances could obviously be observed.

The Respond Surface Methodology (RSM) was applied in this research to find appropriateness in the process. RSM is renowned and widely used in many laboratory experiments to find out correlation between independent and dependent factors by forming equations to simulate the experiment. Moreover, it can better provide levels and degrees of independent factors with satisfy accuracy. 
The appropriateness of the blade number was identified by RSM: Second Order Model which was less complicated and less intricate than other RSM models [22]. The equation can be shown as follow:

$$
y=\beta_{0}+\sum_{i=1}^{k} \beta_{i} x_{i}+\sum_{i=1}^{k} \beta_{i i} x_{i}^{2}+\sum_{i=1}^{k-1} \cdot \sum_{j=i+1}^{k} \beta_{i j} x_{i} x_{j}+\varepsilon
$$

When " $y$ " is dependent factor, $x_{i}$ is factor $\boldsymbol{i} ; \boldsymbol{i}=1,2, \ldots, k$, “ $\boldsymbol{k}$ " is all factors, $\beta_{0}$ is y intercept, $\sum_{i=1}^{k} \beta_{i} x_{i}$ is Linear Effect, $\sum_{i=1}^{k} \beta_{i i} x_{i}^{2}$ is Quadratic effect and $\sum_{i=1}^{k-1} \cdot \sum_{j=i+1}^{k} \beta_{i j} x_{i} x_{j} \quad$ is Cross product effect.

From research on Hydroelectric generator system driven by Vortex force [15-20], waterpower equation is shown as follow:

$$
P_{i}=\rho g Q H
$$

Power output equation is shown as follow:

$$
P_{e}=E I
$$

The values from each equation above are processed to verify corelated system efficiency by equation shown as follow:

$$
\eta=\frac{P_{e}}{P_{i}}
$$

When $\rho=$ water density $\left(1,000 \mathrm{~kg} / \mathrm{m}^{3}\right), \mathrm{g}=$ acceleration from gravity $\left(9.81 \mathrm{~m}^{2} / \mathrm{s}\right)$, $\mathrm{Q}=$ flowrate $\left(\mathrm{m}^{3} / \mathrm{min}\right), N=$ revolutions of the shaft $(\mathrm{rpm}), H=$ water head $(\mathrm{m}), E=$ voltage (volt, V), $I=$ current (Ampere, A) and $P_{e}=$ electrical power (Watts, W).

\section{Results}

\subsection{Propeller turbine}

The result from 12 Propeller turbines testing at different water-flow rate ranged from $0.2-0.6 \mathrm{~m}^{3} / \mathrm{s}$ is shown as follow:

Table 1. Test results for a turbine with a diameter of 0.5 meter.

\begin{tabular}{cccc}
\hline $\mathbf{Q}$ & \multicolumn{3}{c}{ Efficiency $(\%)$} \\
\cline { 2 - 4 }$\left(\mathbf{m}^{\mathbf{3} / \mathbf{s})}\right.$ & $\mathbf{H = 0 . 2} \mathbf{( m )}$ & $\mathbf{H = 0 . 3} \mathbf{( m )}$ & $\mathbf{H = 0 . 4}(\mathbf{m})$ \\
\hline 0.02 & 7.1 & 9.56 & 9.93 \\
0.03 & 9.47 & 11.33 & 10.57 \\
0.04 & 11.2 & 12.47 & 12.08 \\
0.05 & 9.47 & 9.9 & 10.05 \\
0.06 & 8.83 & 8.98 & 8.81 \\
\hline
\end{tabular}

The most efficient turbine (12.47\% of efficiency) has 0.5 -meter diameter with 0.4 -meter height. It was tested at the water-flowrate of $0.4 \mathrm{~m}^{3} / \mathrm{s}$. 
Table 2. Test results for a turbine with a diameter of 0.6 meter.

\begin{tabular}{cccc}
\hline $\mathbf{Q}$ & \multicolumn{3}{c}{ Efficiency $(\%)$} \\
\cline { 2 - 4 }$\left(\mathbf{m}^{3 / \mathbf{s})}\right.$ & $\mathbf{H = 0 . 2} \mathbf{( m )}$ & $\mathbf{H}=\mathbf{0 . 3}(\mathbf{m})$ & $\mathbf{H = 0 . 4}(\mathbf{m})$ \\
\hline 0.02 & 10.12 & 10.49 & 11.79 \\
0.03 & 10.75 & 11.2 & 12.62 \\
0.04 & 12.07 & 12.08 & 12.15 \\
0.05 & 9.75 & 9.54 & 9.83 \\
0.06 & 8.62 & 7.81 & 7.96 \\
\hline
\end{tabular}

The most efficient turbine (12.62\% of efficiency) has 0.6 -meter diameter with 0.3 -meter height. It was tested at the water-flowrate of $0.3 \mathrm{~m}^{3} / \mathrm{s}$.

Table 3. Test results for a turbine with a diameter of 0.7 meter.

\begin{tabular}{cccc}
\hline $\mathbf{Q}$ & \multicolumn{3}{c}{ Efficiency $\%)$} \\
\cline { 2 - 4 }$(\mathbf{m} / \mathbf{s})$ & $\mathbf{H = 0 . 2}(\mathbf{m})$ & $\mathbf{H = 0 . 3}(\mathbf{m})$ & $\mathbf{H = 0 . 4}(\mathbf{m})$ \\
\hline 0.02 & 12.49 & 12.53 & 13.92 \\
0.03 & 11.67 & 11.96 & 12.99 \\
0.04 & 10.83 & 10.13 & 10.14 \\
0.05 & 8.49 & 8.02 & 7.87 \\
0.06 & 7.43 & 6.94 & 6.1 \\
\hline
\end{tabular}

The most efficient turbine (13.92\% of efficiency) has 0.7 -meter diameter with 0.4 -meter height. It was tested at the water-flowrate of $0.2 \mathrm{~m}^{3} / \mathrm{s}$.

Table 4. Test results for a turbine with a diameter of 0.8 meter.

\begin{tabular}{cccc}
\hline $\mathbf{Q}$ & \multicolumn{3}{c}{ Efficiency $(\%)$} \\
\cline { 2 - 4 }$\left(\mathbf{m}^{\mathbf{3} / \mathbf{s})}\right.$ & $\mathbf{H = 0 . 2} \mathbf{( m )}$ & $\mathbf{H = 0 . 3} \mathbf{( m )}$ & $\mathbf{H = 0 . 4} \mathbf{( m )}$ \\
\hline 0.02 & 13.04 & 13.07 & 13.35 \\
0.03 & 12 & 11.8 & 11.59 \\
0.04 & 9.79 & 9.35 & 8.74 \\
0.05 & 7.67 & 7.4 & 6.7 \\
0.06 & 6.29 & 6.06 & 4.9 \\
\hline
\end{tabular}

The most efficient turbine (13.35\% of efficiency) has 0.8-meter diameter with 0.4 -meter height. It was tested at the water-flowrate of $0.2 \mathrm{~m}^{3} / \mathrm{s}$.

The data from table 1- 4 reveals that the Propeller turbine with 0.7-meter diameter and 0.4 -meter height has $13.92 \%$ of efficiency at $0.2 \mathrm{~m}^{3} / \mathrm{s}$ of water speed. It can be explained that increasing turbine's height and diameter ranged from 0.5-0.7 meter creates more blade's surface. With more blade's surface, the turbine can handle more force and more flow speed of the vortex [15]. This increases the efficiency of the system. Although Propeller turbine 
with 0.8-meter diameter has the most blade's surface, there is an amount of resistant force from the housing wall against the turbine. This is due to the closer gap between the edge of the blade and the housing wall. So, the Propeller turbine with 0.8-meter diameter and 0.4meter height has less efficiency than the one with 0.7-meter diameter at the same height because of this reason (see Figure 6).

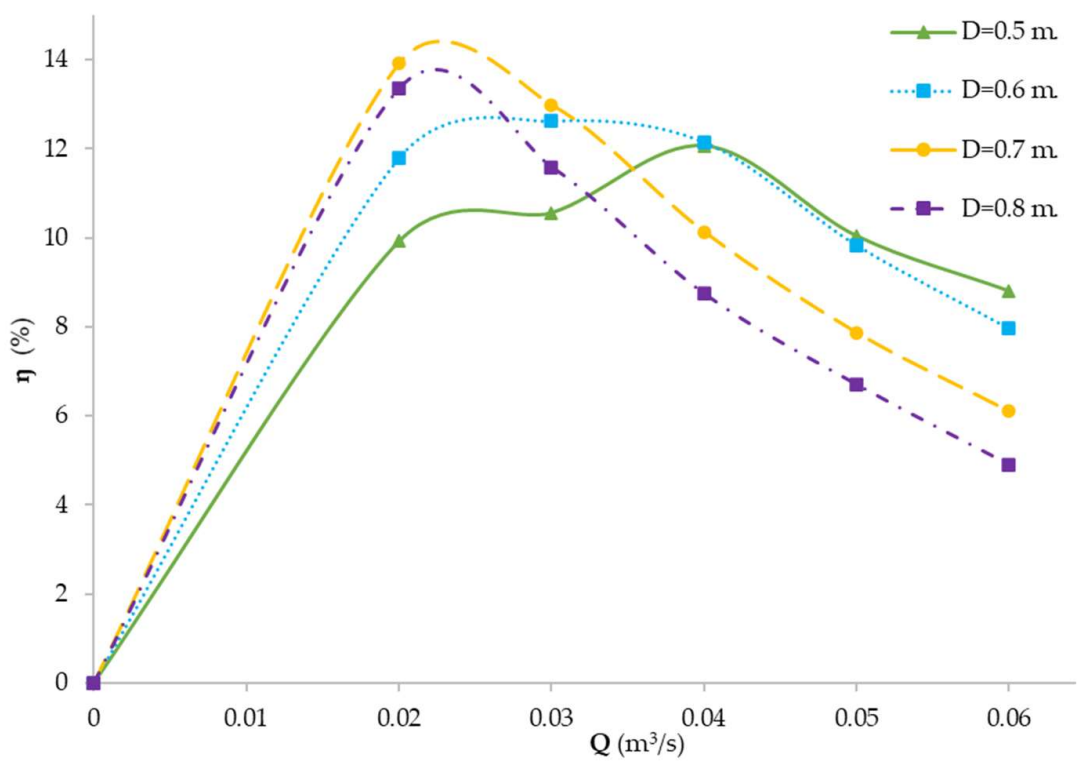

Figure 6. The experimental results of the efficiency obtained when changing the number of turbine blades

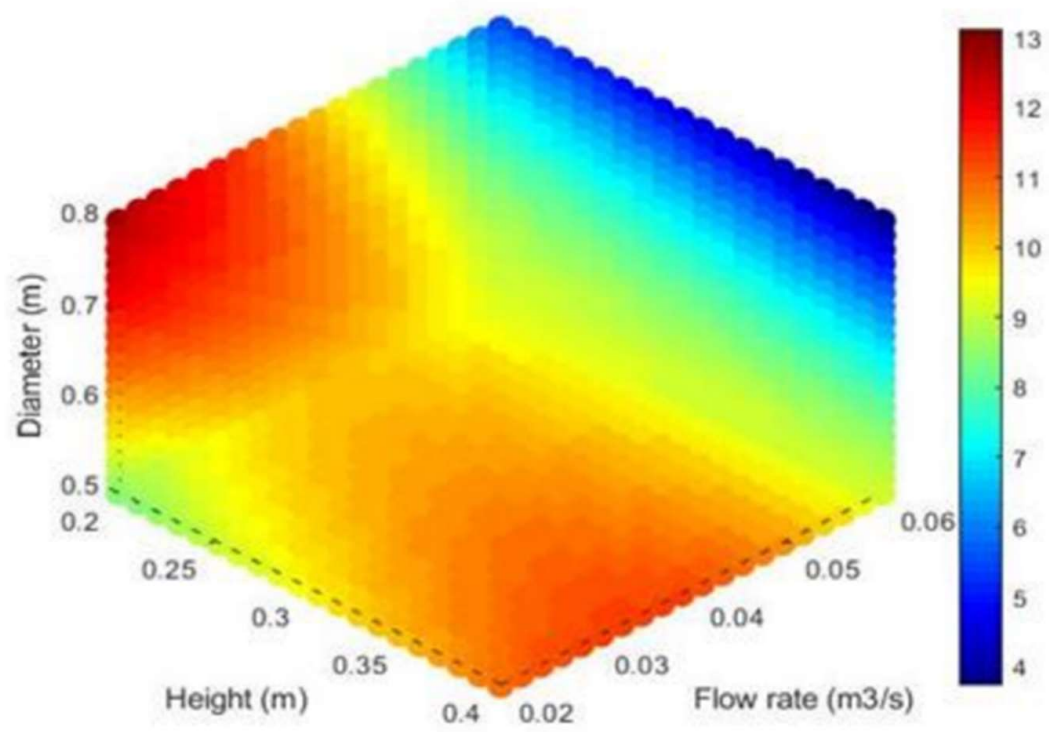

Figure 7. The Respond Surface Methodology (RSM) of Propeller turbines.

The Propeller turbine size that can achieve most efficiency from free-flow vortex is determined by the following RSM equation: 


$$
Y=-27.2516+645.7888 x_{1}+32.579 x_{2}+71.024 x_{3}-0.0030649 x_{1}^{2}-0.1 x_{2}^{2}-29.667 x_{3}^{2}-
$$

$301.25 x_{1} x_{2}-643.433 x_{1} x_{3}-29.56 x_{2} x_{3}$

When $Y=$ overall efficiency, $x \_1=$ water flowrate, $x \_2=$ blade's height, and $x \_3=$ turbine's diameter

From the RSM equation result, Figure 7 indicates that the best blade surface providing most efficiency comes from the Propeller turbine with 0.78-meter diameter and 0.4-meter height at $0.02 \mathrm{~m}^{3} / \mathrm{s}$ water flowrate. The dark red area shows the highest value. The proper diameter length and proper water flow rate within the system can obviously increase the overall system efficiency.

\subsection{Crossflow turbine}

4 Crossflow turbines with 24 blades and same height $(0.3$ meter) were tested at water flow rate ranged from $0.02-0.06 \mathrm{~m}^{3} / \mathrm{s}$. Their diameters are $0.4,0.5,0.6$, and 0.7 meter and the overall efficiency is shown in table 5.

Table 5. The Crossflow turbine at a height of 0.3 meter and has 24 blades.

\begin{tabular}{ccccc}
\hline $\mathbf{Q}$ & \multicolumn{4}{c}{ Efficiency (\%) } \\
\cline { 2 - 5 }$\left(\mathbf{m}^{\mathbf{3} / \mathbf{s})}\right.$ & $\mathbf{D = 0 . 4} \mathbf{( m . )}$ & $\mathbf{D}=\mathbf{0 . 5}(\mathbf{m})$. & $\mathbf{D = 0 . 6}(\mathbf{m})$. & $\mathbf{D = 0 . 7}(\mathbf{m})$. \\
\hline 0.02 & 21.91 & 21.78 & 9.17 & 4.05 \\
0.03 & 19.63 & 12.00 & 5.18 & 2.49 \\
0.04 & 18.35 & 9.79 & 3.62 & 1.68 \\
0.05 & 15.7 & 8.24 & 3.14 & 1.43 \\
0.06 & 13.05 & 7.34 & 2.99 & 1.39 \\
\hline
\end{tabular}

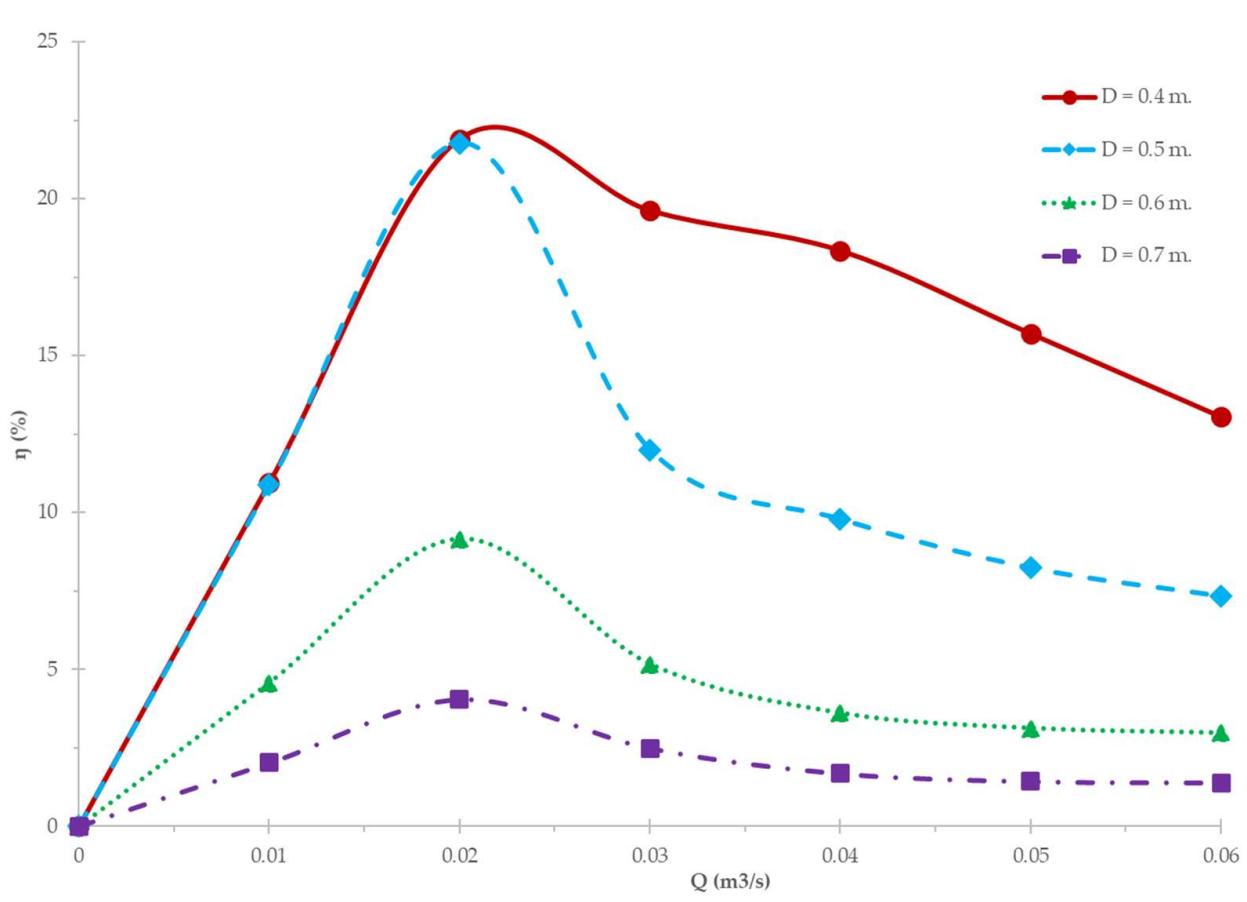

Figure 8. Experimental results of the efficiency obtained when changing the diameter of the turbine. 
The Table 5 indicates that 24 blade Crossflow turbine with 0.3-meter height and 0.4meter diameter can achieve $21.91 \%$ of efficiency at $0.02 \mathrm{~m}^{3} / \mathrm{s}$ water flowrate. This causes by the generator configuration. The turbine housing was laid vertically so the water flowrate was boosted up by the earth gravity. The design of the water flow activity within the system also increased the water flow speed as the speed of water flowing through the drainage is faster than the one flowing through the middle part of the generator. The turbine was mounted 0.02 meter high above the drainage to allow the turbine to get full impact from the vortex. Moreover, the height of the turbine and vortex head were equal letting the vortex to cover all the blades' surface (see Figure 8).

The Crossflow turbine with 0.3-meter height and 0.4-meter diameter was divided into 5 according to the number of the turbine blade $(12,18,24,30$, and 36). They were all tested at the water flowrate ranged from $0.02-0.06 \mathrm{~m}^{3} / \mathrm{s}$. Result is shown in Figure 9.

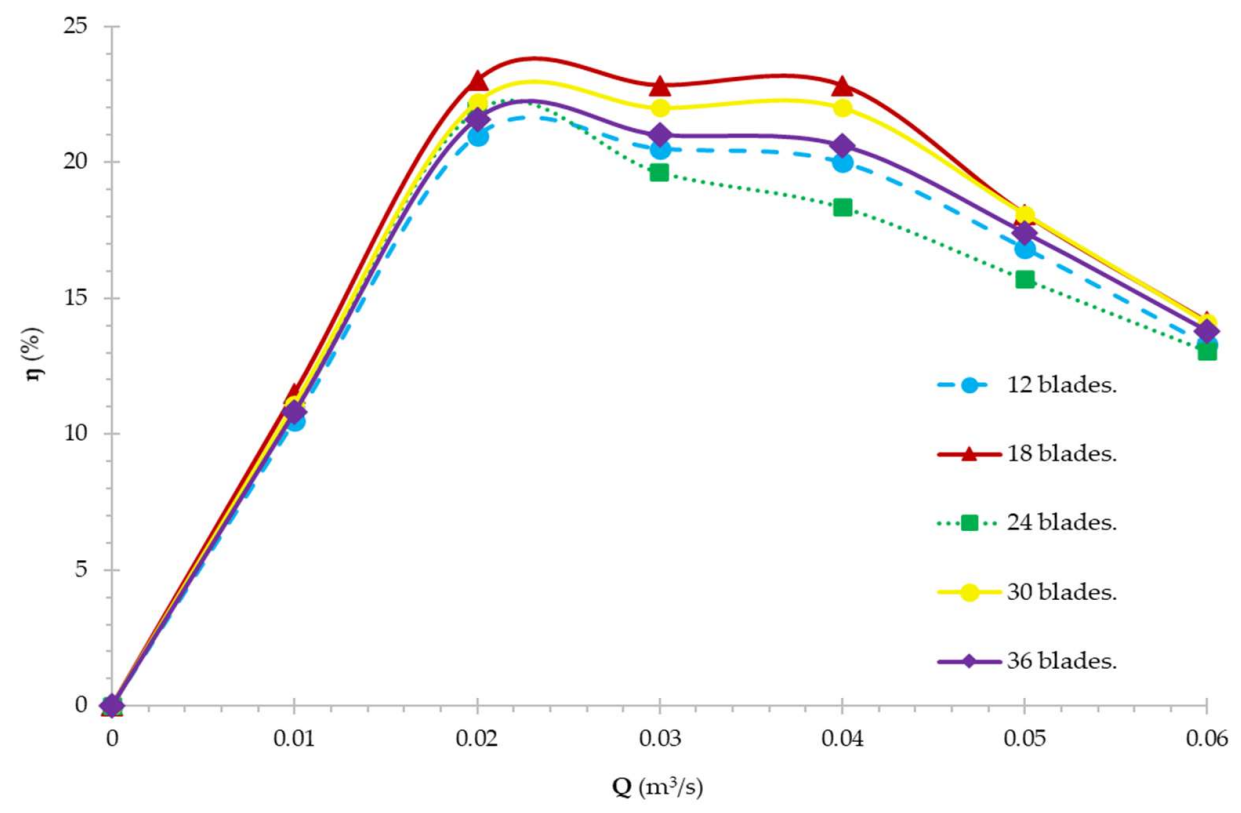

Figure 9. The experimental results of the efficiency obtained when changing the number of turbine blades.

The Figure 9 reveals the correlation between overall efficiency and water flowrate ranged from $0.02-0.06 \mathrm{~m}^{3} / \mathrm{s}$. The 18 blades Crossflow turbine achieved most efficiency $(23.01 \%)$ at $0.02 \mathrm{~m}^{3} / \mathrm{s}$ water flowrate. From the testing, the result shows that number of blade effects overall efficiency of this vortex driven generator [15]. Adding more blades to the Crossflow turbine decreases overall efficiency. Although more blades provide more impact surface, the water flow is limited by the close distance between the blades. When number of blades was set to 12 and 18, the turbines had more distance between the blades. So, in conclusion, the 18 blades Crossflow turbine could achieve the most efficiency because the distance between blades matched with the water flow rate.

The Crossflow turbine size that can achieve most efficiency from free-flow vortex is determined by the following RSM equation:

$$
Y=-91.1990+949.5214 x_{1}+169.555 x_{2}+5.1196 x_{3}-82.1500 x_{1}^{2}-6.40499 x_{2}^{2}-640.5000 x_{3}^{2}
$$

When $Y=$ overall efficiency, $x \_1=$ water flowrate, $x \_2=$ blade's height, and $x \_3=$ turbine's diameter. 


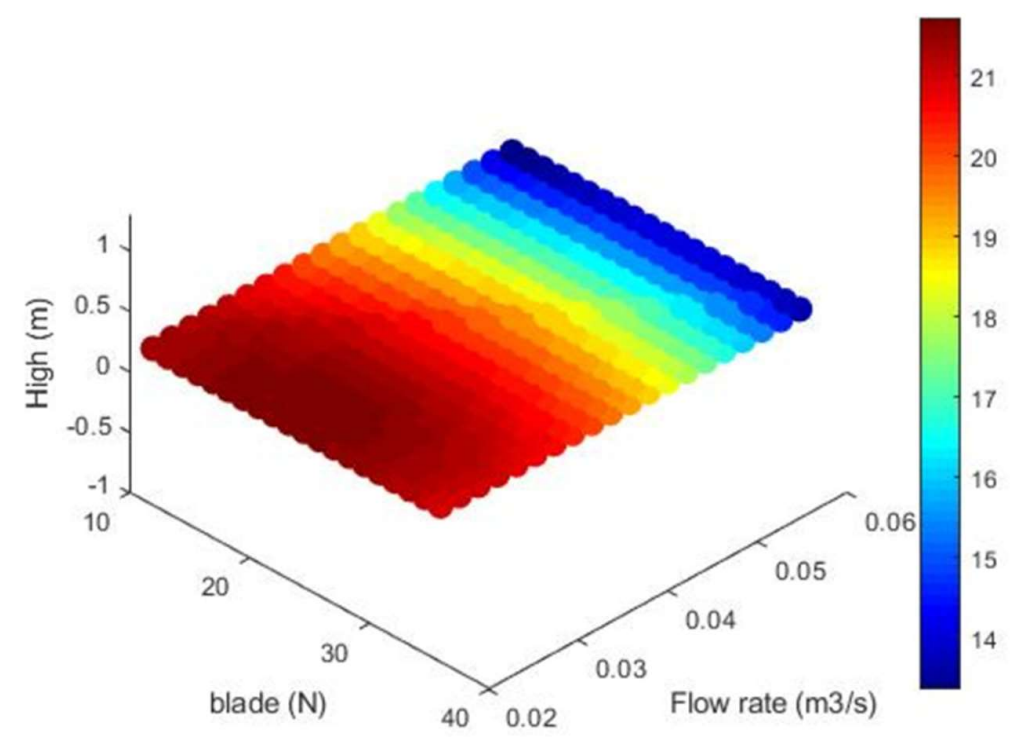

Figure 10. The Respond Surface Methodology (RSM) of Crossflow turbines.

From the RSM equation result, Figure 10 indicates that the best blade surface providing most efficiency comes from the Crossflow turbine with 0.4-meter diameter and 0.3meter height at $0.02 \mathrm{~m}^{3} / \mathrm{s}$ water flowrate. The dark red area shows the highest value. The proper diameter length and proper water flow rate within the system can obviously increase the overall system efficiency.

\subsection{The comparison}

4 Crossflow turbines with 24 blades and same height ( 0.3 meter $)$ were tested at water flow rate ranged from $0.02-0.06 \mathrm{~m}^{3} / \mathrm{s}$. Their diameters are $0.4,0.5,0.6$, and 0.7 meter and the overall efficiency is shown in table 5 .

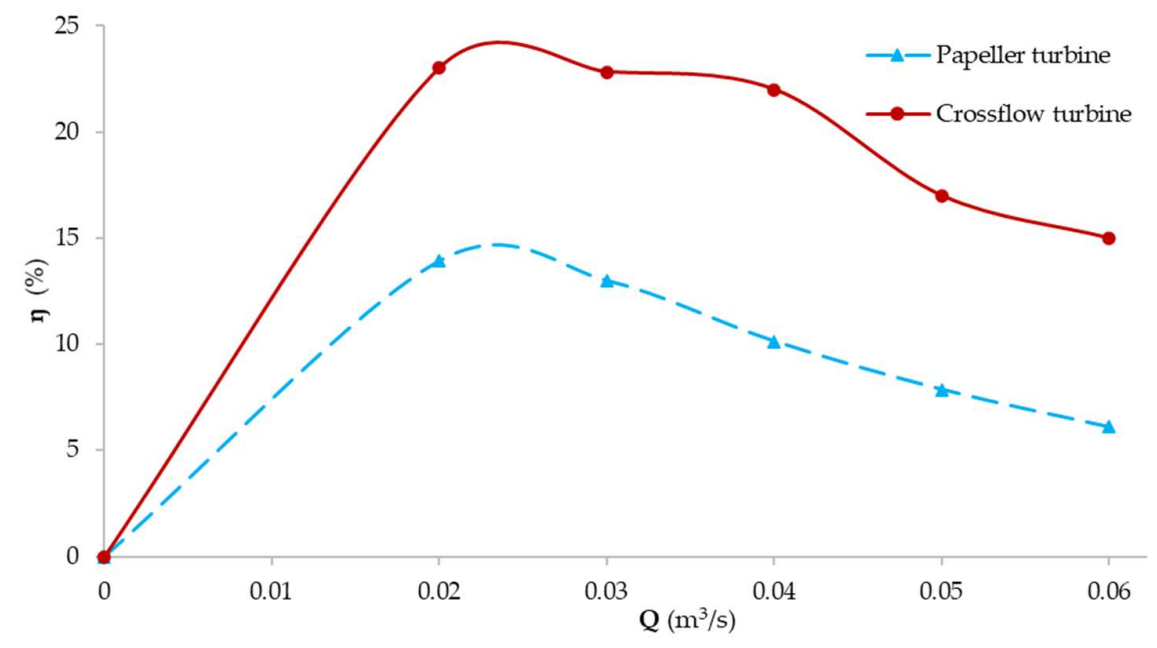

Figure 11. Compare the maximum efficiency of both types of turbines.

Testing all of turbines in the same setting (vortex driven generator system) reveals that 5 blades Propeller turbine with 0.4-meter height and 0.7-meter diameter [15] achieved most efficiency of $13.92 \%$ at $0.02 \mathrm{~m}^{3} / \mathrm{s}$ water flowrate. On the other hand, 18 blades 
Crossflow turbine with 0.3-meter height and 0.4-meter diameter achieved most efficiency of $13.92 \%$ at $0.02 \mathrm{~m}^{3} / \mathrm{s}$ water flowrate (see Figure 11 ).

\section{Discussion and Conclusions}

Verifying the right turbine size that matches the turbine housing design significantly effects the overall efficiency of the Hydroelectric generator system driven by vortex. This research discovers that 5 blades Propeller turbine with 0.4-meter height and 0.7-meter diameter achieved $13.92 \%$ of efficiency at $0.02 \mathrm{~m} 3 / \mathrm{s}$ water flowrate whereas 18 blades Crossflow turbine with 0.3-meter height and 0.4-meter diameter achieved 13.92\% of efficiency at the same water flowrate. At $0.02 \mathrm{~m}^{3} / \mathrm{s}$ water flowrate, the Crossflow turbine has more overall efficiency than Propeller at $9.09 \%$. From the comparison result of the two turbines used in 0.5-meter-high cylinder-shaped generator housing, turbine types, turbine size (height and diameter), number of blades, and water flowrates are key factors that affect the overall efficiency. The Crossflow turbine can achieve more efficiency than Propeller turbine in this generator system.

Author Contributions: Conceptualization, P.S. and R.S.; methodology, P.S. and R.S.; software, P.S. and R.S.; validation, R.S.; formal analysis, P.S. and R.S.; investigation, P.S. and R.S.; resources, P.S. and R.S. data curation, P.S. and R.S.; writing-original draft preparation, P.S.; writing-review and editing, R.S.; visualization, P.S.; supervision, R.S. project administration, P.S.; All authors have read and agreed to the published version of the manuscript.

Funding: This research received no external funding.

Institutional Review Board Statement: Not applicable.

Informed Consent Statement: Not applicable

Data Availability Statement: Not applicable.

Conflicts of Interest: The authors declare no conflict of interest.

Acknowledgments: Researchers are grateful to the Farm Engineering and Automation Technology Research Group (FEAT), Department of Mechanical Engineering Khon kaen University and Rajamangala University of Technology Isan Surin Campus for the support of tools and equipment used in this research.

\section{References}

1. International Energy Agency. Key World Energy Statistics 2017. IEA Publications. International Energy Agency, 2017.

2. Mohibullah, M.; Radzi, A. M.; Hakim, M.I.A. Basic design aspects of micro hydro power plant and its potential development in Malaysia. In PECon 2004. Proceedings. National Power and Energy Conference, IEEE, 2004, 220-223. doi: https://doi.org/10.1109/PECON.2004.1461647.

3. Teuteberg, B.H. Design of a pump-as-turbine for an abalone farm. M.Eng. dissertation, University of Stellenbosch, Stellenbosch, 2010.

4. Yaakob, O.B.; Ahmed, Y.M.; Elbatran, A.H.; Shabara, H.M. A review on micro hydro gravitational vortex power and turbine systems. J Teknol (Sci Eng), 2014, 69, 7, 1-7. doi: https://doi.org/10.11113/jt.v69.3259.

5. Paish, O. Micro-hydropower: status and prospects. Proceedings of the Institution of Mechanical Engineers, Part A: Journal of Power and Energy, 2002, 216, 1, 31-40. doi: https://doi.org/10.1243/095765002760024827.

6. Dhakal, S.; Nakarmi, S.; Pun, P.; Thapa, A.B.; Bajracharya, T.R. Development and Testing of Runner and Conical Basin for Gravitational Water Vortex Power Plant. Journal of the Institute of Engineering, 2014, 10, 1, 140-148. doi: https://doi.org/10.3126/jie.v10i1.10895.

7. Dhakal, S.; Timilsina, A.B.; Dhakal, R.; Fuyal, D.; Bajracharya, T.R.; Pandit, H.P.; Amatya, N.; Nakarmi, A.M. Comparison of cylindrical and conical basins with optimum position of runner: Gravitational water vortex power plant. Renewable and Sustainable Energy Reviews, 2015, 48, 662-669. https://doi.org/10.1016/j.rser.2015.04.030 
8. Franz, Z. Zotloterer Gravitational Vortex power plant. ZOTLÖTERER SMART-Energy-Systems. 2021. Available online: http://www.zotloeterer.com/welcome/gravitation-water-vortex-power-plants (accessed on 02 August 2021).

9. Chen, Y.L.; Wu, C.; Ye, M.; Ju, X.M. Hydraulic characteristics of vertical vortex at hydraulic intakes. Journal of Hydrodynamics Ser. B, 2017, 19, 2, 143-149. doi: https://doi.org/10.1016/S1001-6058(07)60040-7.

10. Shi, X.M.; Yang, F.; Dai, R.; Chen, T.J.; Wu, Y.L. Simulation of free-surface vortex produced by a rotating cylindrical wall below a static barrel. IOP Conference Series: Earth and Environmental Science, 2012, 15, 052034. doi: https://iopscience.iop.org/article/10.1088/1755-1315/15/5/052034/pdf

11. Shabara, H.M.; Yaakob, O.B.; Ahmed, M.; Elbatran, A.H.; Muhammad, S.M. CFD Validation for Efficient Gravitational Vortex Pool System. Jurnal Teknologi (Sciences E Engineering), 2015, 74, 5, 97-100. doi: https://doi.org/10.11113/jt.v74.4648.

12. Wanchat, S.; Suntivarakorn, R. Preliminary design of a vortex pool for electrical generation. Advanced Science Letters, 2012, 13, 1, 173-177. doi: https://doi.org/10.1166/asl.2012.3855.

13. Kueh, T.C.; Beh, S.L.; Rilling, D.; Ooi, Y. Numerical Analysis of Water Vortex Formation for the Water Vortex Power Plant. International Journal of Innovation: Management and Technology, 2014, 5, 2, 111-115.

14. Li, H.F.; Chen, H.X.; Ma, Z.; Zhou, Y. Formation and influencing factors of free surface vortex in barrel with a central orifice at bottom. Journal of Hydrodynamics, 2009, 21, 2, 238-244. doi: https://doi.org/10.1016/S1001-6058(08)60141-9.

15. Sritram, P.; Suntivarakorn, R. The effects of blade number and turbine baffle plates on the efficiency of free-vortex water turbines. IOP Conf. Series: Earth and Environmental Science, 2019, 257, 012040. doi: https://iopscience.iop.org/article/10.1088/17551315/257/1/012040/meta.

16. Ullah, R.; Cheema, T.A.; Saleem, A.S.; Ahmad, S.M.; Chattha, J.A.; Park, C.W. Preliminary experimental study on multi-stage gravitational water vortex turbine in a conical basin. Renewable Energy, 2020, 145, $2516-2529$. https://doi.org/10.1016/j.renene.2019.07.128.

17. Sritram, P.; Treedet, W.; Suntivarakorn, R. Effect of Turbine Materials on Power Generation Efficiency from Free Water Vortex Hydro Power Plant. IOP Conference Series: Material Science and Engineering, 2015, 103, 1-7. doi: https://iopscience.iop.org/article/10.1088/1757-899X/103/1/012018/pdf.

18. Wanchat, S.; Suntivarakorn, R.; Wanchat, S.; Tonmit, K.; Kayanyiem, P. A Parametric Study of a Gravitation Vortex Power Plant. Advanced Materials Research, 2013, 805, 811-817. doi: https://doi.org/10.4028/www.scientific.net/AMR.805-806.811.

19. Sritram, P.; Suntivarakorn, R. Comparative Study of Small Hydropower Turbine Efficiency at Low Head Water. Energy Procedia, 2017, 138, 646-650. doi: https://doi.org/10.1016/j.egypro.2017.10.181

20. Suntivarakorn, R.; Wanchat, S.; Suwanasri. S. An Experimental Study of Electricity Production Using a Vortex Turbine in a Gravitational Water Vortex Power Plant. GMSARN Int. Conf. on Innovative Energy, Environment, and Development in GMS, 2016, 16-18.

21. Adhikari R.; Wood, D. The Design of High Efficiency Crossflow Hydro Turbines: A Review and Extension. Energies, 2018, 11, 2, 267. doi: https://doi.org/10.3390/en11020267

22. Pradubsri, W.; Chomtee, B.; Thongteeraparp, A. A Study of Small Response Surface Designs for the Full Second Order Model and a Set of Reduced Models in a Spherical Region. Science and Technology Journal, 2015, 23, 3, 362-376. 